\title{
New Class of Closed Sets in Bitopological Spaces
}

\author{
S.V. Vani ${ }^{1^{*}}$, G. Priscilla Pacifica ${ }^{2}$ \\ ${ }^{1}$ St.Mary's College, Thoothukudi, TN, INDIA \\ ${ }^{2}$ St.Mary's College, Thoothukudi, TN, INDIA \\ *Corresponding Author: vanikathir16@gmail.com
}

Available online at: www.isroset.org

Accepted 17/Aug/2018, Online 30/Aug/2018

\begin{abstract}
The concept of bitopological space was first introduced by J.C.Kelly in 1963 (i.e) a non-empty set $X$ equipped with two arbitrary topologies $\tau_{1}$ and $\tau_{2}$. The concept of generalized closed sets plays a significant role in general topology and these are the research topics of many Topologists worldwide.In 1970 Norman Levine introduced the concept of generalization of closed sets in topological spaces and he defined the semi-open sets and semi-continuity in bitopological spaces. In this paper we introduce a new class of generalized closed sets namely (i,j) $-g^{\# \#}$-closed sets in bitopological spaces (i.e)a subset $A$ of a bitopological space $\left(\mathrm{X}, \tau_{1}, \tau_{2}\right)$ is called $(\mathrm{i}, \mathrm{j})-g^{\# \#}$-closed if $\tau_{\mathrm{j}}-\mathrm{cl}(\mathrm{A}) \subseteq \mathrm{U}$, whenever $\mathrm{A} \subseteq \mathrm{U}, U$ is $\tau_{\mathrm{i}}-g^{\#}$-open in $\left(\mathrm{X}, \tau_{1}, \tau_{2}\right)$ and some of the properties were discussed. The class of $(\mathrm{i}, \mathrm{j})-g^{\# \#}$-closed sets settled in between the class of $(\mathrm{i}, \mathrm{j})-g^{*}$ - closed sets and the class of $(\mathrm{i}, \mathrm{j})$ - gs- closed sets.Some of the basic properties of $(\mathrm{i}, \mathrm{j})-\mathrm{g}^{\# \#}$ - closed sets are investigated.
\end{abstract}

Keywords: Topological spaces , Bitopological spaces, $(\mathrm{i}, \mathrm{j})-g^{\# \#}$-closed sets.

AMS Mathematics Subject Classification 2010: 54A05, 54A10

\section{INTRODUCTION}

A triple $\left(X, \tau_{1}, \tau_{2}\right)$ consisting of a non-empty set together with a pair of Topologies $\tau_{1} \& \tau_{2}$ on $X$, is defined to be a bitopological space by J.C.Kelley as introduced through the famous mathematical paper entitled as "Bitopological spaces"and published in proceeding of London Mathematical Society,1963.Such a space,equipped with two arbitrary topologies, is beyond any doubt an original and fundamental work. As a recall,in 1963, a semi-open set A was defined as the subset $\mathrm{A}$ of a topological space $(\mathrm{X}, \tau)$ iff there exist $\mathrm{O} \in \tau$ such that $\mathrm{O} \subseteq A \subseteq \operatorname{cl}(\mathrm{O})$ and denoted by s-open or equivalently iff $\mathrm{A} \subseteq \operatorname{cl}(\operatorname{int}(\mathrm{A}))$.In 1970,generalized closed sets were introduced and studied by N.Levine.He conceptualized a generalized closed set as a subset A of a topological space $(\mathrm{X}, \tau)$ for which $\mathrm{A} \subseteq \operatorname{int}(\operatorname{cl}(\operatorname{int}(\mathrm{A})))$ and is denoted by $\alpha$-open set .In 1985,T.Fukutake projected the concept of g-closed sets for bitopological spces through the mathematical paper "On Generalized closed sets In Bitopological spaces"published in Bull.Fuscnoka Univ.Ed.Part III,1986.In this paper,we introduce a new class of generalized closed sets namely $(i, j)$ - $g^{\# \#}$-closed sets in bitopological spaces. The class of $(\mathrm{i}, \mathrm{j})$ -

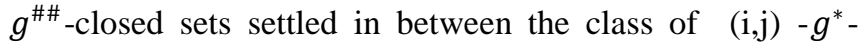
closed sets and the class of $(\mathrm{i}, \mathrm{j})$ - gs- closed sets.Some of the basic properties of $(\mathrm{i}, \mathrm{j})-\mathrm{g}^{\# \#}$ - closed sets are investigated.

\section{PRELIMINARIES}

Definition 2.1:A subset A of a topological space $(X, \tau)$ is called

1. a semi-open set if $\mathrm{A} \subseteq \operatorname{cl}(\operatorname{int}(\mathrm{A}))$ and semi-closed set if $\operatorname{int}(\operatorname{cl}(\mathrm{A})) \subseteq \mathrm{A}$.

2. an $\alpha$-open set if $\mathrm{A} \subseteq \operatorname{int}(\operatorname{cl}(\operatorname{int}(\mathrm{A})))$ and an $\alpha$ closed set if $c l(\operatorname{int}(\operatorname{cl}(\mathrm{A}))) \subseteq \mathrm{A}$.

3. a generalized closed set(briefly $g$-closed) if $c l(\mathrm{~A}) \subseteq \mathrm{U}$ whenever $\mathrm{A} \subseteq U$ and $U$ is open in $(\mathrm{X}, \tau)$.

4. a generalized semi-closed set(briefly gs-closed)if $\operatorname{scl}(\mathrm{A}) \subseteq U$ whenever $\mathrm{A} \subseteq U$ and $U$ is open in $(\mathrm{X}, \tau)$.

5. a generalized star closed set (briefly $g^{*}$-closed) if $\operatorname{cl}(\mathrm{A}) \subseteq \mathrm{U}$ whenever $\mathrm{A} \subseteq U U$ is g-open in $(\mathrm{X}, \tau)$.

6. $g^{\#}$-semi-closed if $\operatorname{scl}(\mathrm{A}) \subseteq U$ whenever $\mathrm{A} \subseteq U$ and $U$ is $\alpha g$-open in $(X, \tau)$.

7. a semi-generalized closed (briefly sg-closed) if $\operatorname{scl}(\mathrm{A}) \subseteq U$ whenever $\mathrm{A} \subseteq U$ and $U$ is semi-open in $(\mathrm{X}, \tau)$.

If $\mathrm{A}$ is a subset of $\mathrm{X}$ with the topology $\tau$, then the closure of $\mathrm{A}$ is denoted by $\tau-\operatorname{cl}(A)$ or $\operatorname{cl}(A)$.The interior of $\mathrm{A}$ is denoted by $\tau-\operatorname{int}(A)$ and the complement of $\mathrm{A}$ in $\mathrm{X}$ denoted by $A^{c}$. 
Definition:2.3 A subset A of a bitopological space

$\left(\mathrm{X}, \tau_{i}, \tau_{j}\right)$ is called

1. a $(i, j)$-g-closed if $\tau_{j}-c l(A) \subseteq U$ whenever $A \subseteq U$ and $\mathrm{U}$ is open in $\tau_{i}$.

2. a $(i, j)-g^{*}$-closed if $\tau_{j}-c l(A) \subseteq U$ whenever $A \subseteq U$ and $\mathrm{U}$ is g-open in $\tau_{i}$.

3. a $(i, j)$-gs-closed if $\tau_{j}-\operatorname{scl}(A) \subseteq U$ whenever $A \subseteq U$ and $\mathrm{U}$ is open in $\tau_{i}$.

4. a $(i, j)-\psi$-closed or $\mathrm{s} g^{*}$-closed $\tau_{j}-\mathrm{s} \operatorname{cl}(A) \subseteq U$ whenever $A \subseteq U$ and $\mathrm{U}$ is sg-open in $\tau_{i}$.

5. a $(i, j)$-sg-closed $\tau_{j}-\operatorname{scl}(A) \subseteq U$ whenever $A \subseteq U$ and $\mathrm{U}$ is semi- open in $\tau_{i}$.

\section{RELATIONSHIPS OF $(i, j)-g^{\# \#-C L O S E D ~ S E T S ~}$ WITH SOME OTHER CLOSED SETS}

We introduce the following definition:

Definition 3.1: A subset $A$ of a bitopological space $\left(X, \tau_{1}, \tau_{2}\right)$ is called $(\mathrm{i}, \mathrm{j})-g^{\# \#}$-closed if $\tau_{j}-\operatorname{cl}(A) \subseteq$ $U$,whenever $A \subseteq U, U$ is $\tau_{i}-g^{\#}$-open in $\left(X, \tau_{1}, \tau_{2}\right)$.

Example 3.2: Let $X=\{a, b, c\}$ be a bitopological space with topologies

$\tau_{1}=\{\varphi,\{a\},\{b\},\{a, b\}, X\}$

$\tau_{2}=\{\varphi,\{a\},\{a, b\}, X\}$.

$\tau_{1}-g^{\#}$-open sets are $\{\varphi,\{a\},\{b\},\{a, b\}, X\}$

Then (i, j)-g $g^{\# \#-c l o s e d ~ s e t s ~ a r e ~}\{\varphi,\{c\},\{a, c\},\{b, c\}, X\}$

Proposition 3.3: Every $\tau_{j}$-closed set $A$ is $(i, j)-g^{\# \#}$ closed but not conversely.

Proof: Assume that $A$ is $\tau_{j}$-closed , $A \subseteq U$ and $\mathrm{U}$ is $g^{\#}$ open in $\tau_{i}$.

Since $A$ is $\tau_{j}$-closed, $\operatorname{cl}(A)=A$.

There fore $\tau_{j}-c l(A) \subseteq U$.Hence $\mathrm{A}$ is $(\mathrm{i}, \mathrm{j})-g^{\# \#}$-closed.

Remark 3.4: Converse of the above theorem need not be true as seen from the following example.

Example 3.5: Let $X=\{a, b, c\}$ be a bitopological space with topologies

$\tau_{1}=\{\varphi,\{a\},\{b\},\{a, b\}, X\}$

$\tau_{2}=\{\varphi,\{a\},\{a, b\}, X\}$.Then the set $\{a, c\}$ is $(\mathrm{i}, \mathrm{j})-g^{\# \#}$-closed but not $\tau_{2}$-closed.
6. a $(i, j)-g^{\#}$-closed $\tau_{j}-c l(A) \subseteq U$ whenever $A \subseteq U$ and $\mathrm{U}$ is $\alpha g$-open in $\tau_{i}$.

7. a $(i, j)$-s $g^{* *}$-closed $\tau_{j}$-scl$(A) \subseteq U$ whenever $A \subseteq U$ and $\mathrm{U}$ is $\mathrm{s} g^{*}$-open in $\tau_{i}$.

8. a $(i, j)-\alpha^{* *}$-closed if $\tau_{j}-\operatorname{cl}(A) \subseteq U$ whenever $A \subseteq U$ and $\mathrm{U}$ is $\alpha^{*}$-open in $\tau_{i}$.

9. a $(i, j)$-strongly $g^{*}$-closed if $\tau_{j}-\operatorname{cl}(\operatorname{int}(A)) \subseteq U$ whenever $A \subseteq U$ and $\mathrm{U}$ is g-open in $\tau_{i}$.

10. a $(i, j)$-strongly $\alpha^{* *}$-closed if $\tau_{j}-\operatorname{cl}(\operatorname{int}(A)) \subseteq U$ whenever $A \subseteq U$ and $\mathrm{U}$ is $\alpha^{*}$-open in $\tau_{i}$.

Proposition 3.6: Every ( $\mathrm{i}, \mathrm{j})-g^{*}$-closed is $(\mathrm{i}, \mathrm{j})-\mathrm{g}^{\# \#}$-closed but not conversely.

Proof: Assume that $A$ is (i, j)- $g^{*}$-closed.Let $A \subseteq U$ and $U$ is $\tau_{i}$-g-open.

since every $\tau_{i}$-g-open is $\tau_{i}$ - $\alpha g$-open.

Hence $A$ is (i, j) $-g^{\# \#}$-closed.

Remark 3.7: Converse of the above theorem need not be true as seen from the following example.

Example 3.8: Let $X=\{a, b, c\}$ be a bitopological space with topologies

$\tau_{1}=\{\varphi,\{b\}, X\}$

$\tau_{2}=\{\varphi,\{c\}, X\}$.Then the set $\{b, c\}$ is $(\mathrm{i}, \mathrm{j})-g^{\# \#}$-closed but not $(\mathrm{i}, \mathrm{j})-g^{*}$-closed.

Proposition 3.9: Every (i, j)- $g^{\#}$-closed sets are (i, j)- $g^{\# \#}$ closed but not conversely.

Proof: Assume that $A$ is $(\mathrm{i}, \mathrm{j})-g^{\#}$-closed, $A \subseteq U$ and $U$ is $\tau_{i}-\alpha g$-open.

Hence $A$ is $(\mathrm{i}, \mathrm{j})-g^{\# \#}$-closed.

Remark 3.10: Converse of the above proposition need not be true as seen from the following example

Example 3.11: Let $\mathrm{X}=\{a, b, c\}$ be a bitopological space with topologies

$\tau_{1}=\{\varphi,\{b\}, X\}$

$\tau_{2}=\{\varphi,\{c\}, X\}$. Then the set $\{c\}$ is $(\mathrm{i}, \mathrm{j})-g^{\# \#}$-closed but not (i, j)- $g^{\#}$-closed.

Proposition 3.12: If $A$ is $(\mathrm{i}, \mathrm{j})-g^{\# \#}$-closed then $A$ is $(\mathrm{i}, \mathrm{j})$ $\alpha^{* *}$-closed. 
Proof:Assume that $A$ is $g^{\# \#}$-closed, $A \subseteq U$ and $U$ is $\tau_{i}-g^{\#}$ open.

Since every $\tau_{i}-g^{\#}$-open set is $\tau_{i}$ - $\alpha^{*}$-open.

Hence $A$ is $(\mathrm{i}, \mathrm{j})-\alpha^{* *}$-closed.

Conversely suppose that $A$ is $(\mathrm{i}, \mathrm{j})-\alpha^{* *}$-closed, whenever $A \subseteq U$ and $U$ is $\tau_{i^{-}} \alpha^{*}$-open.

Since every $\tau_{i}-\alpha^{*}$-open is $\tau_{i}-g^{\#}$-open.

Hence $A$ is $(\mathrm{i}, \mathrm{j})-g^{\# \#}$-closed.

Proposition 3.13: If $A$ is (i,j)-strongly $\alpha^{* *}$-closed then $A$ is $(i, j)-g^{\# \#}$-closed.

Proof:Assume that $A$ is $(\mathrm{i}, \mathrm{j})$-strongly $\alpha^{* *}$-closed,whenever $A \subseteq U$ and $U$ is $\tau_{i^{-}} \alpha^{*}$-open.

Since every $(\mathrm{i}, \mathrm{j})-\alpha^{* *}$-closed is $(\mathrm{i}, \mathrm{j})$-strongly- $\alpha^{* *}$-closed.

By previous theorem, $A$ is (i, j)- $g^{\# \#}$-closed.

Conversely suppose that $A(\mathrm{i}, \mathrm{j})-g^{\# \#}$-closed.

Obviously by the previous theorem we get the required result.

Proposition 3.14: Every ( $i, j)-g^{\# \#}$-closed set is $(i, j)$-gsclosed.

Proof: Assume that $A$ is $(\mathrm{i}, \mathrm{j})-g^{\# \#}$-closed, $A \subseteq U$ and $U$ is $\tau_{i}-g^{\#}$-open.

Since every $\tau_{i}-g^{\#}$-open is $\tau_{i}$-open.

Hence $A$ is $(\mathrm{i}, \mathrm{j})$-gs-closed.

Remark 3.15: Converse of the above proposition need not be true from the following example.

Example 3.16: Let $X=\{a, b, c\}$ be a bitopological space with topologies

$\tau_{1}=\{\varphi,\{a\},\{a, b\}, X\}$,

$\tau_{2}=\{\varphi,\{a\},\{b\},\{a, b\}, X\}$ then the set $A=\{b\}$ is (i, j) -gsclosed but not $(\mathrm{i}, \mathrm{j})-g^{\#}$ closed.

Remark 3.17: (i,j)-sg-closedness is independent of $(i, j)-$

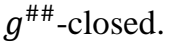

Example 3.18: Let $X=\{a, b, c\}$ be a bitopological space with topologies $\tau_{2}=\{\varphi,\{a\},\{a, b\}, X\}$

$\tau_{1}=\{\varphi,\{a\},\{b\},\{a, b\} X\}$. Then the set $A=\{b\}$ is (i, j)-sg closed but not (i, j)- $g^{\# \#}$ closed.

Also the set $A=\{a, c\}$ is (i, $\mathrm{j})-g^{\# \#-c l o s e d ~ b u t ~ n o t ~}(\mathrm{i}, \mathrm{j})$-sg closed.

Hence (i, j) -sg-closedness is independent of $(i, j)-g^{\# \#}$. closed.

Remark 3.19: (i, j) -strongly- $g^{*}$-closedness is independent of $(\mathrm{i}, \mathrm{j})-g^{\# \#}$-closed.

Example 3.20: Let $X=\{a, b, c\}$ be a bitopological space with topologies

$\tau_{1}=\{\varphi,\{b\}, X\}$

$\tau_{2}=\{\varphi,\{c\}, X\}$.Then the set $A=\{b, c\}$ is $(\mathrm{i}, \mathrm{j})-g^{\# \#}$-closed but not (i, j)-strongly- $g^{*}$-closed.

Also the set $A=\{b\}$ is $(\mathrm{i}, \mathrm{j})$-strongly- $g^{*}$-closed but not (i, j)- $g^{\# \#-c l o s e d . ~}$

Hence (i,j)-strongly- $g^{*}$-closedness is independent of $(\mathrm{i}, \mathrm{j})-g^{\# \# \text {-closed. }}$

Remark 3.21: $(\mathrm{i}, \mathrm{j})-g^{\# \#}$-closedness is independent of $(\mathrm{i}, \mathrm{j})-\psi$-closed.

Example 3.22: Let $\mathrm{X}=\{a, b, c\}$ be a bitopological space with topologies

$\tau_{1}=\{\varphi,\{a\},\{b\},\{a, b\}, X\}$

$\tau_{1}=\{\varphi,\{a\},\{a, b\}, X\}$.Then the set $A=\{a, c\}$ is (i,j) $g^{\# \#}$ closed but not $(\mathrm{i}, \mathrm{j})-\psi$-closed.Also the set $A=\{b\}$ is $(\mathrm{i}, \mathrm{j})-\psi$-closed but not $(\mathrm{i}, \mathrm{j})-g^{\# \#}$-closed.

Hence $(i, j)-g^{\# \#}$-closedness is independent of $(i, j)-\psi-$ closed.

Remark 3.23: $(i, j)-g^{\# \#}$-closedness is independent of $(\mathrm{i}, \mathrm{j})$-s $g^{* *}$-closed.

Example 3.24: Let $X=\{a, b, c\}$ be a bitopological space with topologies

$\tau_{1}=\{\varphi,\{b\}, X\}$

$\tau_{2}=\{\varphi,\{c\}, X\}$.Then the set $A=\{c\}$ is $(i, j)-g^{\# \#}$-closed but not $(i, j)$-strongly-s $g^{* *}$-closed.

Also the set $A=\{b\}$ is $(\mathrm{i}, \mathrm{j})$-strongly-s $g^{* *}$-closed but not (i, j)- $g^{\# \#-c l o s e d . ~}$ 
The above results can be represented in the following figure:

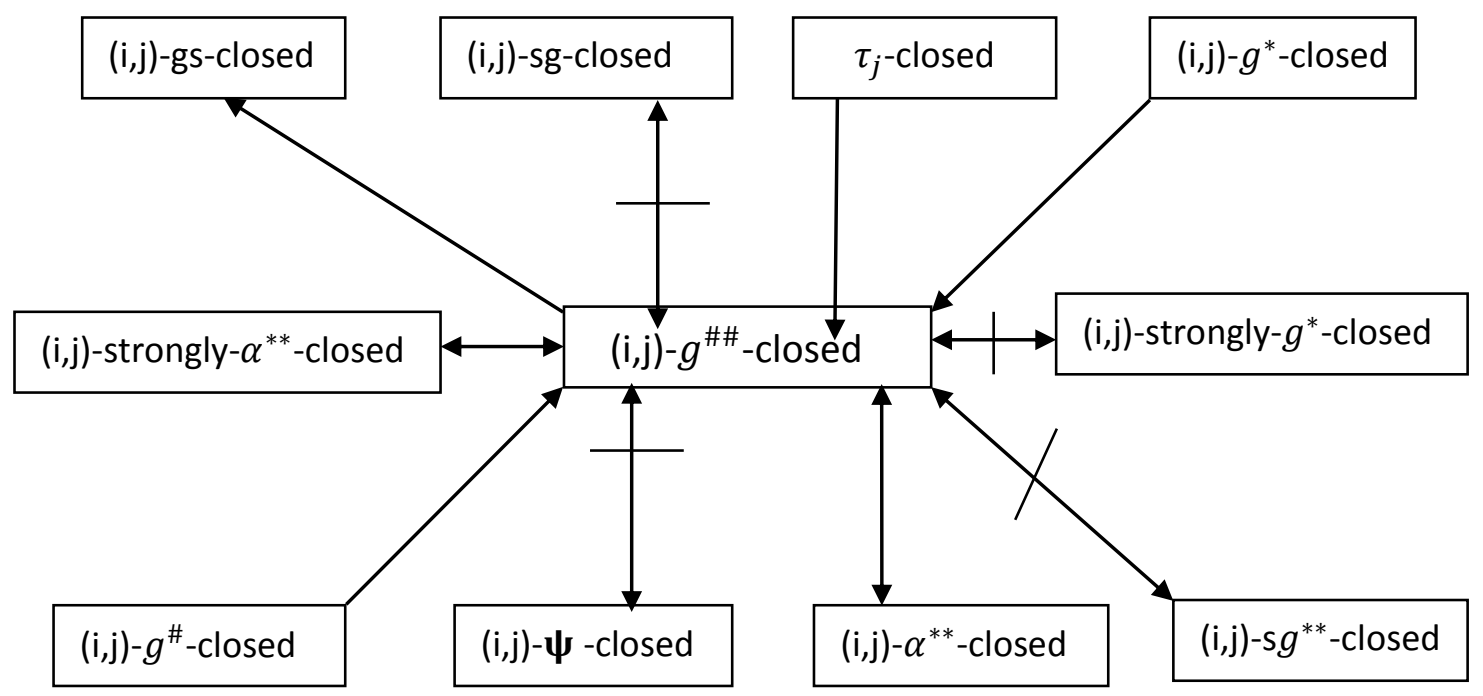

Where A $\rightarrow$ B represents A implies B and B need not imply A

$\mathrm{A} \longleftrightarrow \mathrm{B}$ represents $\mathrm{A}$ and $\mathrm{B}$ are independent.

\section{BASIC PROPERTIES OF $(i, j)-g^{\# \#}$-CLOSED SETS}

Proposition 4.1: Union of any two $(\mathrm{i}, \mathrm{j})-g^{\# \#}$-closed sets is again $(\mathrm{i}, \mathrm{j})-g^{\# \#}$-closed sets.

Proof:Let A and B be (i, j)- $g^{\# \#}$-closed sets.

Then $A \subseteq U$ and $B \subseteq U$ where $\mathrm{U}$ is $\tau_{j}-g^{\#}$-open.

This implies $\tau_{j}-c l(A) \subseteq U$ and $\tau_{j}-c l(B) \subseteq U$.

Now $\tau_{j}-\operatorname{cl}(A \cup B)=\tau_{j}-\operatorname{cl}(\mathrm{A}) \cup \tau_{j}-\mathrm{cl}(\mathrm{B}) \subseteq U$

Hence $\tau_{j}-\operatorname{cl}(A \cup B) \subseteq U$, whenever $A \cup B \subseteq U$ and $\mathrm{U}$ is $g^{\#}$-open in $\tau_{i}$.

Therefore AUB is (i, j)- $g^{\# \#-c l o s e d ~ s e t s . ~}$

Remark 4.2: The intersection of two (i, j)- $g^{\# \#-c l o s e d ~ s e t s ~}$ need not be $(\mathrm{i}, \mathrm{j})-\mathrm{g}^{\# \#}$-closed sets.

Example 4.3: Let $X=\{a, b, c\}$ be a bitopological space with topologies

$\tau_{1}=\{\varphi,\{a\}, X\}, \quad \tau_{2}=\{\varphi,\{a\},\{a, b\} X\}$.

Here $A=\{a, c\}$ and $B=\{a, b\}$ are $(\mathrm{i}, \mathrm{j})-g^{\# \#}$-closed sets, but $\mathrm{A} \cap \mathrm{B}=\{a\}$ is not a $(\mathrm{i}, \mathrm{j})-g^{\# \#}$-closed sets.

Remark 4.4: $(\mathrm{i}, \mathrm{j})-g^{\# \#}$-closed is generally not equal to $(\mathrm{i}, \mathrm{j})-g^{\# \#-c l o s e d}$ as seen from the following example.
Example 4.5: Let $\mathrm{X}=\{a, b, c\}$ be a bitopological space with topologies

$\tau_{1}=\{\varphi,\{b\},\{c\},\{a, c\},\{b, c\}, X\}$

$\tau_{2}=\{\varphi,\{a\},\{b, c\}, X\}$.

Here $A=\{a, c\} \subset(\mathrm{j}, \mathrm{i})-g^{\# \#}$-closed,

but $A=\{a, c\} \not \subset(\mathrm{i}, \mathrm{j})-g^{\# \#}$-closed set.

Therefore $(\mathrm{i}, \mathrm{j})-g^{\# \#}$-closed $\neq(\mathrm{j}, \mathrm{i})-g^{\# \#}$-closed.

\section{CONCLUSIONS}

Through the above findings, this paper has attempted to compare $(i, j)-g^{\# \#}$ closed sets with other closed sets in bitopological spaces And also in terms of a grill.An attempt of this paper is to state that the definitions and result in obtaining several characterizations and enable to study various properties as well.

\section{ACKNOWLEDGEMENT}

The authors would like to thank the reviewers for their valuable comments and helpful suggestions for improvement of the original manuscript.

\section{REFERENCES}

[1] Arockiarani,studies on generalizations of generalized closed sets and maps in topological spaces,Ph.d.,Thesis,Bharathiar Univ,Coimbatore, 1997. 
[2] Bhattacharyia.P and Lahiri.B.K, semi generalized closed sets in Topology, Rend.circ, Math.Palermo, 19(2) (1970), 89-96.

[3] R.Devi, K.Balachandran and H.Maki, semi-generalized closed maps and generalized closed maps, Mem.Eac.Sci.Kochi Unvi.Ser.A.Math.,14(1993), 41-54.

[4] L.Elvina Mary,E.L.Mary Tency,A study on $(i, j)-(G s)^{*}$-closed sets in bitopological spaces,IJOSER, vol 3 issue 1 january-2015.

[5] J.C.Kelley,Proc.London Math.Sci.,13(1963),71-89.
[6] Levine.N.Generalised closed sets in topology, Rend, circ, Math.palermo, (19)(2)(1970), 86-96.

[7] Mashhour.A.S.,AbdEl-deeb.S.N., $\alpha$-open mappings, Acta.Math.Hungar, 41 (1983),213-218

[8] S.Pauline Mary Helen.M, SindhuSurya.R, (i,j) strongly $a^{* *}$-closed sets in Bitopological spaces,IJMTT(2014).

[9] M.K.R.S.Veerakumar, between closed sets and g-closed sets, Mem.Fac.Kochi Unvi.ser.A, Math., 17(1996), 33-42. 